\title{
A new wine Torulaspora delbrueckii killer strain with broad antifungal activity and its toxin-encoding double-stranded RNA virus
}

\author{
Manuel Ramírez ${ }^{1 *}$, Rocío Velázquez ${ }^{1}$, Matilde Maqueda ${ }^{1}$, Antonio López-Piñeiro² and \\ Juan C. Ribas ${ }^{3}$
}

' Departamento de Ciencias Biomédicas (Área de Microbiología, Antiguo Rectorado), Facultad de Ciencias, Universidad de Extremadura, Badajoz, Spain, ${ }^{2}$ Departamento de Biología Vegetal, Ecología y Ciencias de la Tierra, Facultad de Ciencias, Universidad de Extremadura, Badajoz, Spain, ${ }^{3}$ Instituto de Biología Funcional y Genómica, CSIC/Universidad de Salamanca, Salamanca, Spain

\section{OPEN ACCESS}

Edited by:

Alberto Mas,

Rovira i Virgili University, Spain

Reviewed by:

Maurizio Ciani,

Università Politecnica delle Marche,

Italy

Benoit Divol,

Stellenbosch University, South Africa

*Correspondence:

Manuel Ramírez,

Departamento de Ciencias Biomédicas (Área de Microbiología,

Antiguo Rectorado), Facultad

de Ciencias, Universidad

de Extremadura, 06071 Badajoz,

Spain

mramirez@unex.es

Specialty section:

This article was submitted to

Food Microbiology,

a section of the journa

Frontiers in Microbiology

Received: 31 July 2015 Accepted: 03 September 2015

Published: 15 September 2015

Citation:

Ramírez M, Velázquez R, Maqueda $M$, López-Piñeiro A and Ribas JC (2015)

A new wine Torulaspora delbrueckii killer strain with broad antifungal activity and its toxin-encoding

double-stranded RNA virus.

Front. Microbiol. 6:983.

doi: 10.3389/fmicb.2015.00983
Wine Torulaspora delbrueckii strains producing a new killer toxin (Kbarr-1) were isolated and selected for wine making. They killed all the previously known Saccharomyces cerevisiae killer strains, in addition to other non-Saccharomyces yeasts. The Kbarr-1 phenotype is encoded by a medium-size $1.7 \mathrm{~kb}$ dsRNA, TdV-Mbarr-1, which seems to depend on a large-size $4.6 \mathrm{~kb}$ dsRNA virus (TdV-LAbarr) for stable maintenance and replication. The TdV-Mbarr-1 dsRNA was sequenced by new generation sequencing techniques. Its genome structure is similar to those of $S$. cerevisiae killer $M$ dsRNAs, with a $5^{\prime}$-end coding region followed by an internal A-rich sequence and a $3^{\prime}$-end non-coding region. Mbarr- 1 RNA positive strand carries cis acting signals at its $5^{\prime}$ and $3^{\prime}$ termini for transcription and replication respectively, similar to those RNAs of yeast killer viruses. The ORF at the $5^{\prime}$ region codes for a putative preprotoxin with an $\mathrm{N}$-terminal secretion signal, potential Kex2p/Kexlp processing sites, and N-glycosylation sites. No relevant sequence identity was found either between the full sequence of Mbarr-1 dsRNA and other yeast $\mathrm{M}$ dsRNAs, or between their respective toxin-encoded proteins. However, a relevant identity of TdV-Mbarr-1 RNA regions to the putative replication and packaging signals of most of the M-virus RNAs suggests that they are all evolutionarily related.

Keywords: wine, yeast, Torulaspora, killer, virus, dsRNA

\section{Introduction}

The Saccharomyces cerevisiae killer strains have been grouped so far into four types (K1, K2, K28, and Klus) based on their killing profiles and lack of cross-immunity. Members of each group can kill non-killer yeasts as well as killer yeasts belonging to the other killer yeast types. These killer yeasts secrete protein toxins that are also lethal to other yeast species (Rodríguez-Cousiño et al., 2011). Each killer yeast is immune to its own toxin or to toxins produced by strains of the same killer type (Schmitt and Breinig, 2006). S. cerevisiae killer toxins (K1, K2, K28, and Klus) are encoded by the positive strand of medium-size (1.6-2.4 kb) dsRNA of yeast viruses (M1, M2, M28, and Mlus, respectively). The RNA $5^{\prime}$-end region contains an ORF that codes for the toxin precursor or preprotoxin (pptox), which also provides immunity to its own killer toxin. The four toxin-coding 
M dsRNAs show no sequence identity with each other (Schmitt and Tipper, 1995; Rodríguez-Cousiño et al., 2011). These M viruses depend on a second large-size $(4.6 \mathrm{~kb})$ dsRNA helper virus, LA, for maintenance and replication. LA provides the capsids and polymerase in which both LA and $M$ dsRNAs are separately encapsidated and replicated, and the $M$ dsRNAs contain some stem-loop structures that mimic those LA dsRNA signals required for genome packaging or replication [reviewed by Schmitt and Breinig (2006)]. The LA genome code for two proteins, the major coat protein Gag and a minor Gag-Pol fusion protein translated by a -1 ribosomal frameshifting mechanism and that contains all the activities required for virus propagation (Icho and Wickner, 1989; Dinman and Wickner, 1992; Fujimura et al., 1992; Park et al., 1996).

The cis signals required for RNA packaging and replication are located in the $3^{\prime}$-terminal regions of the positive strands of both LA and M RNAs (Wickner et al., 1995; Rodríguez-Cousiño et al., 2011). The signal for transcription initiation has been proposed to be present in the $5^{\prime}$-end first 25 nucleotides of LA RNA, probably in the very $5^{\prime}$-terminal sequence itself $\left(5^{\prime}\right.$-GAAAAA). This $5^{\prime}$ terminal recognition element is also present in the $5^{\prime}$ end of $\mathrm{M} 1$, M2, M28, and Mlus RNAs (Fujimura et al., 1990; RodríguezCousiño et al., 2011). The M1, M2, or M28 ORF is translated into a pptox that subsequently enters the secretory pathway for further processing and secretion as a mature toxin. The unprocessed pptox consists of an $\mathrm{N}$-terminal signal sequence necessary for its import into the endoplasmic reticulum lumen, followed by the $\alpha$ - and $\beta$-subunits of the mature toxin separated from each other, in the case of $\mathrm{K} 1$ and $\mathrm{K} 28$, by a potentially $\mathrm{N}$-glycosylated $\gamma$-sequence. The signal peptide is removed in the endoplasmic reticulum, and $\mathrm{N}$-glycosylation and disulphide bond formation occurs. Then, in a late Golgi compartment, protease processing takes place involving Kex2 and Kex1 proteases. Finally, the toxin is secreted as an active $\alpha / \beta$ heterodimer, with the two subunits being covalently linked by one or more disulphide bonds (Wickner et al., 1995; Schmitt and Breinig, 2006). All this processing is also believed to occur in Klus pptox according to its predicted amino acid sequence (Rodríguez-Cousiño et al., 2011). There are some other non-Saccharomyces killer yeasts containing a similar set of dsRNA helper and satellite viruses responsible for their killer phenotype, such as Hanseniaspora uvarum, Zygosaccharomyces bailii, or Ustilago maydis (Magliani et al., 1997).

Torulaspora delbrueckii was one of the first nonSaccharomyces yeasts to be released onto the market, and is probably the most used for winemaking. Controlled inoculation with this yeast is broadly recommended for improving the complexity and enhancing some specific characteristics of wines (Jolly et al., 2006; Azzolini et al., 2015). However, its impact on wine quality is still far from satisfactory, mostly because of the difficulty in controlling the desired participating proportion of $T$. delbrueckii with respect to the other wine yeast species involved in the same must fermentation process, mainly S. cerevisiae-like yeasts. As with most non-Saccharomyces yeasts, T. delbrueckii has less fermentation vigor and slower growth rate than $S$. cerevisiae under usual wine fermentation conditions, being quickly overcome by wild or inoculated S. cerevisiae strains
(González-Royo et al., 2014). Additionally, cell-to-cell contact has also been suggested to explain this decline of T. delbrueckii when it is in the presence of S. cerevisiae (Nissen et al., 2003; Renault et al., 2013). Thus, knowledge of the Saccharomyces and Torulaspora wine yeast interactions during wine fermentation needs to be improved to better control each yeast's participation rate (Ciani et al., 2010). The availability of good-fermenting T. delbrueckii killer strains, able to kill the omnipresent wild Saccharomyces yeasts, would be an interesting tool to achieve the inoculated yeast's dominance of the must fermentation process, so that the result would be the desired improvement in quality of the wine. The isolation of T. delbrueckii killer strains has been described (Sangorrín et al., 2007a,b), but no detailed phenotype or genotype analysis of these killer strains has as yet been reported.

The objective of the present work was the phenotypic analysis and genotypic characterization of new T. delbrueckii killer strains (Kbarr-1) isolated from the Barraecas valley in Spain. We addressed the following questions: (i) antifungal spectrum of the Kbarr-1 toxin, (ii) isolation, sequencing, and characterization of Mbarr-1 dsRNA satellite viruses, and (iii) analysis of Mbarr1 genome organization and its preprotoxin ORF as compared with the dsRNA of other $M$ viruses. The possible evolutionary relationship between these groups of viral $\mathrm{M}$ dsRNAs is discussed.

\section{Materials and Methods}

\section{Yeast Strains and Media}

The new $T$. delbrueckii Kbarr wine yeasts are prototrophic strains isolated from spontaneous fermentations of grapes from vineyards of the Albarregas (Barraecas in Latin) river valley in Spain. The industrial use of these Kbarr yeasts is under patent application. The yeast strains used in this work are summarized in Table 1.

Standard culture media were used for yeast growth (Guthrie and Fink, 1991). YEPD contained 1\% yeast extract, 2\% peptone, and $2 \%$ glucose. YEPD + cyh is YEPD supplemented with cycloheximide (cyh) to a final concentration of $2 \mu \mathrm{g} / \mathrm{ml}$. Synthetic minimal medium (SD) contained $0.67 \%$ Yeast Nitrogen Base (without amino acids; with ammonium sulfate, Difco), and $2 \%$ glucose. The corresponding solid media also contained $2 \%$ agar. Standard procedures were used for sporulation of yeast cultures (Kaiser et al., 1994). Diploid cells grown on YEPD plates for 2 days at $30^{\circ} \mathrm{C}$ were transferred to sporulation plates ( $1 \%$ potassium acetate, $0.1 \%$ yeast extract, $0.05 \%$ glucose, $2 \%$ agar) and incubated for $7-30$ days at $25^{\circ} \mathrm{C}$ until cells sporulated.

\section{Determination of Yeast Killer Activity}

Killer activity was tested on low-pH (pH 4.0 or 4.7) methylene blue plates ( 4 or $4.7 \mathrm{MB}$; Kaiser et al., 1994) seeded with $100 \mu \mathrm{l}$ of a 48-h grown culture of the sensitive strain (Ramírez et al., 2004). Depending on the experiments, the strains being tested for killer activity were either loaded as $4 \mu \mathrm{l}$ drops of stationary phase cultures, patched from solid cultures, or replica plated onto the seeded MB plates. Then the plates were incubated for $4-8$ days at 12 or $20^{\circ} \mathrm{C}$. 
TABLE 1 | Yeast strains used in this study.

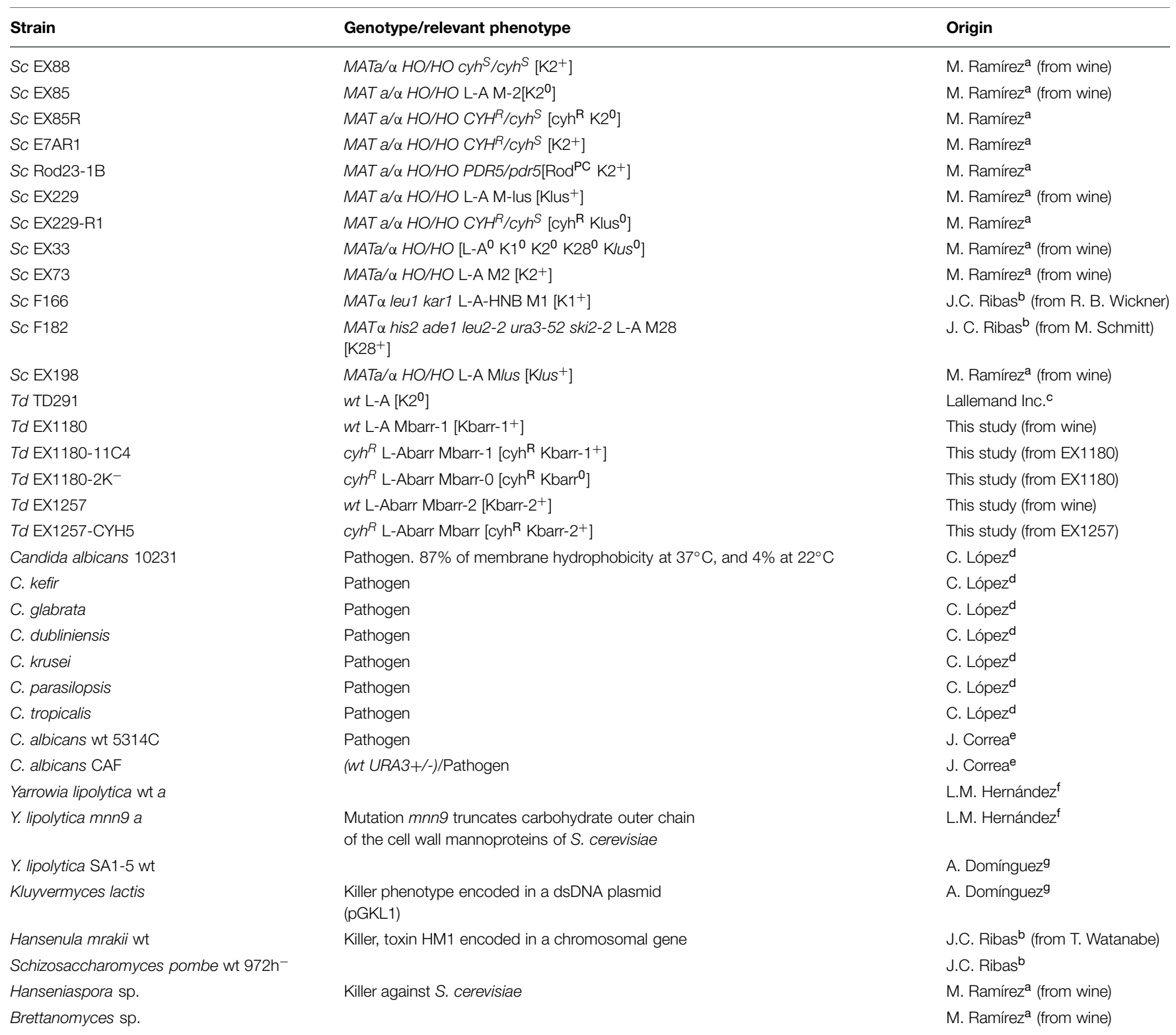

aM. Ramirez, Departamento de Ciencias Biomédicas, Universidad de Extremadura, Badajoz, Spain.

bJ. C. Ribas, Instituto de Biología Funcional y Genómica, CS/C/Universidad de Salamanca, Salamanca, Spain.

'Lallemand Inc., 19 Rue des Briquetiers, BP 59, 31702 Blagnac Cedex, France.

${ }^{d}$ C. López, Departamento de Ciencias Biomédicas, Universidad de Extremadura, Badajoz, Spain.

e J. Correa, Departamento de Ciencias Biomédicas, Universidad de Extremadura, Badajoz, Spain.

f L. M. Hernández, Departamento de Ciencias Biomédicas, Universidad de Extremadura, Badajoz, Spain.

'A. Domínguez, Departamento de Microbiología y Genética, Universidad de Salamanca, Salamanca, Spain.

Sc, Saccharomyces cerevisiae; Td, Torulaspora delbrueckii.

\section{Total Nucleic Acid Preparation and Nuclease Digestion}

The procedure for routine dsRNA and mitochondrial DNA (mtDNA) minipreps was described previously (Maqueda et al., 2010). Basically, the cells were suspended in $10 \mathrm{mM}$ TrisHCI ( $\mathrm{pH}$ 7.5) buffer containing $0.1 \mathrm{M} \mathrm{NaCl}, 10 \mathrm{mM}$ EDTA and $0.2 \%$ SDS, thereafter, an equal volume of phenol ( $\mathrm{pH} 8.0)$ was added. This mixture was incubated at room temperature for $30 \mathrm{~min}$ with shaking. After centrifugation, the nucleic acids recovered in the aqueous phase were precipitated with isopropanol, washed with $70 \%$ ethanol, dried, and dissolved in TE buffer $\mathrm{pH}$ 8.0. Digestion of DNA was done with DNAse I (RNAsefree, Fermentas Life Sciences) according to the manufacturer's specifications. Digestion of RNA was performed with RNAse A (Sigma-Aldrich) following the manufacturer's indications. For selective degradation of single-stranded RNA, samples were 
incubated with RNAse A $(10 \mu \mathrm{g} / \mathrm{ml})$ in the presence of $0.5 \mathrm{M}$ $\mathrm{NaCl}$ for $30 \mathrm{~min}$ at $37^{\circ} \mathrm{C}$. Samples were then processed through phenol/chloroform/isoamyl alcohol extraction to inactivate the enzyme before analysis through agarose gel electrophoresis (Rodríguez-Cousiño et al., 2011).

\section{Nucleic Acid Analysis for Yeast Strain Typing and Identification of Torulaspora Species}

The procedure for virus dsRNA analysis has been described previously (Maqueda et al., 2010). The samples $(4 \mu \mathrm{l})$ were directly separated in $1 \times$ TAE-1\% agarose gel electrophoresis for virus dsRNA analysis. Nucleic acids were visualized on a UV transilluminator after ethidium bromide staining of the gels and photographed with a Gel Doc 2000 (Bio-Rad). The data analysis was performed using Diversity Database software (Bio-Rad). The nucleic acid bands were typed by Rf, and band assignment was determined by Rf values plus or minus $2 \%$ error. The identification of Torulaspora species by restriction fragment length polymorphism (RFLP) analysis of the internal transcribed spacers (ITS) of ribosomal DNA was done as described previously (Esteve-Zarzoso et al., 1999).

\section{PCR Amplification, Sequencing of 185 Ribosomal DNA (rDNA), and Yeast Identification}

The PCR was performed directly from the nucleic acid minipreps with the kit pReTaq Ready-To-Go PCR Beads (Amersham Biosciences), with the 18S rDNA specific primers EukA (AACCTGGTTGATCCTGCCAGT) and EukB (TGATCCTTCTGCAGGTTCACCTAC; Medlin et al., 1988; Díez et al., 2001). The thermocycler protocol was an initial denaturation step of $95^{\circ} \mathrm{C}$ for $2 \mathrm{~min}$, followed by 35 cycles of denaturing at $95^{\circ} \mathrm{C}$ for $15 \mathrm{~s}$, annealing at $55^{\circ} \mathrm{C}$ for $15 \mathrm{~s}$, and extension at $72^{\circ} \mathrm{C}$ for $2 \mathrm{~min}$; and a final extension at $72^{\circ} \mathrm{C}$ for $10 \mathrm{~min}$. The amplification products were purified with the "Jetquick PCR purification Spin Kit" (Genomed) following the manufacturer's recommendations. The purified rDNA PCR fragment from each isolated microorganism was sent to a sequencing service (Secugen, Madrid, Spain). The 18S rDNA gene sequences were edited with the software Chromas v. $1.45^{1}$, and analyzed against those in GenBank using Blast (Altschul et al., 1990). Sequences of $>99 \%$ similarity to previously published data available at $\mathrm{NCBI}^{2}$ were binned into the same species.

\section{Viral dsRNA Purification}

Total nucleic acid preparation from T. delbrueckii EX1180 strain (killer Kbarr-1) was obtained by the procedures mentioned above (Maqueda et al., 2010). After 1\% agarose gel electrophoresis, the slower-moving dsRNA band $(4.6 \mathrm{~kb})$ and the faster-moving dsRNA band $(1.7 \mathrm{~kb})$ were cut off from the gel and purified with RNaid Kit (Q-Biogene) following the manufacturer's indications. This procedure was repeated until more than $20 \mu \mathrm{g}$ of each purified dsRNA was obtained.

${ }^{1}$ http://www.technelysium.com.au/chromas.html

${ }^{2}$ http://ncbi.nlm.nih.gov

\section{Preparation and Sequencing of cDNA Libraries from Purified Viral dsRNA}

The purified dsRNA samples were sent to the Unidad de Genómica Cantoblanco (Fundación Parque Científico de Madrid, Spain) for cDNA library preparation and next generation sequencing (NGS). Libraries from TdV-Mbarr-1 (1.7 kb dsRNA purified band) were prepared with the "TruSeq RNA Sample Preparation kit" (Illumina) following the company's instructions, and using $200 \mathrm{ng}$ of purified dsRNA as input (quantified with Picogreen). Briefly, this protocol started at the fragmentation step, skipping the RNA purification step as the viral dsRNA had been previously purified as mentioned above. Thereafter, $15 \%$ DMSO was added to the Illumina fragment-prime solution before incubation at $94^{\circ} \mathrm{C}$ for $8 \mathrm{~min}$ to facilitate the dsRNA denaturation. The first strand of cDNA was synthesized using random primers, $\mathrm{dTVN}$ and $\mathrm{dABN}$ oligonucleotides (Isogen Life Science), and SuperScriptIII retrotranscriptase. The dTVN and $\mathrm{dABN}$ oligonucleotides were added to improve the retrotranscription of the expected central poly(A) region of the $M$ virus. Thereafter, the second cDNA strand synthesis, end repair, 3 -ends adenylation, and ligation of the TruSeq adaptors were done (Illumina). These adaptor oligonucleotides included signals for further amplification and sequencing, and also included short sequences referred to as indices which allowed multiplexing in the sequencing run. An enrichment procedure based on PCR was then performed to amplify the library, ensuring that all molecules in the library included the desired adaptors at both ends. The number of PCR cycles was adjusted to 12 and the final amplified libraries were checked on a BioAnalyzer 2100 (Agilent Technology). The libraries were denatured prior to seeding on a flow cell, where clusters were formed, and sequenced using $2 \times 80-2 \times 150$ sequencing runs on a MiSeq instrument.

\section{dsRNA Sequence Assembling}

The obtained cDNA sequences were analyzed and assembled by Biotechvana (Technological Park of Valencia, Spain). As no high-identity reference sequence was available for TdV-Mbarr1 sequence assembly, its full-length sequence was reconstructed using the following strategy. First, SOAP deNOVO2 (Luo et al., 2012) was used to obtain a de novo assembly based on two Illumina libraries, trying multiple assembly attempts with scaffolding and insert size of 200 and varying the Kmer value (with 47 being the most effective Kmer in reported sequences with a minimal number of undetermined positions filled with "Ns"). This K47 assembly comprised several contigs and scaffolds, none of them showing the expected typical features of viral M RNAs such as a $5^{\prime}$ GAAAA-like motif or a large poly(A) trait in the middle of the sequence. To filter the sample, contigs with size shorter than 300 nucleotides were removed from the contig file, while the remaining contigs were used as input to the NR database of the NCBI via the BLASTX search protocol (Altschul et al., 1997) implemented in the software GPRO 1.1 (Futami et al., 2011). The BLASTX results did not report similarity to any viral M-like RNA sequence described in the scientific literature; conversely, highly significant similarity was found between several contigs/scaffolds and some known 
viral RNA sequences (LA, LBC, and others) or host transcripts. These supposed contaminating sequences were also filtered from the assembly. Assuming that our Mbarr-1 sequence may have resulted fragmented during the assembly procedure because of the low complexity in the middle of the sequence containing a putative central poly(A), a manual procedure for sequence assembly was used as follows. Bowtie2 (Langmead et al., 2009) and two ad hoc selected scripts were used to filter all raw reads corresponding to the contaminant sequences by mapping the two Illumina libraries against the contaminant sequences. Then we manually searched the new cleansed Illumina libraries for new raw reads containing a prominent central poly $(\mathrm{A})$ trait, or its complementary poly $(\mathrm{T})$, to manually construct contigs based on at least 10 reads containing the poly(A). Interestingly, only one contig passed this filter. This contig was enlarged by aligning other reads that made a contig with its $5^{\prime}$ and $3^{\prime}$ ends. In doing so, a manually constructed contig of 300 nucleotides with a central 78-mer poly(A), and well defined and informative $5^{\prime}$ and $3^{\prime}$ ends, was obtained. We then searched the K47 assembly for sequences matching these two $5^{\prime}$ and $3^{\prime}$ ends of the poly(A) contig with at least 100 nucleotides. Two contigs of the K47 assembly were identified under this strategy, and used to resolve a contig consisting in an almost full-length sequence of TdVMbarr-1 RNA containing approximately 1500 nucleotides. This sequence was also enlarged as much as possible by selecting again other raw reads (from the cleansed Illumina libraries) making a contig with both the $5^{\prime}$ and $3^{\prime}$ ends of the reconstructed sequence. The final sequence resulted in a 1705 nucleotide contig showing the expected 5' GAAAAA and the typical domain architecture of viral M RNAs. Finally, Bowtie2 (Langmead and Salzberg, 2012) was used to map the cleansed Illumina libraries over the reconstructed final contig in order to obtain a consensus sequence of TdV-Mbarr-1 RNA genome. Visual navigation of the resulting BAM file with the IGV browser (Thorvaldsdottir et al., 2013) showed full coverage of the whole RNA sequence thus validating the methodological approach taken in reconstructing the full-length Mbarr-1 RNA genome.

\section{Miscellaneous}

DNA manipulations (enzyme digestions, PCR, and electrophoresis) were done following standard methods according to (Sambrook et al., 1989). Most of the enzymes were from Promega or Sigma. Synthetic oligonucleotides were from Biomers.

\section{Nucleotide Sequence Accession Number}

The TdV-Mbarr-1 cDNA nucleotide sequence and the encoded Mbarr-1 protein appear in NCBI/GenBank under GenBank accession number KT429819.

\section{Results}

\section{Phenotypic Characterization of Kbarr Killer Yeasts}

We analyzed the killer phenotype of 1264 Saccharomyces-like colonies isolated from 112 spontaneous fermentations of grapes collected from different vineyards of the "Ribera del Guadiana" region (Spain) during several vintages. The killer strains were compared to the previously known $S$. cerevisiae K1, K2, K28 and Klus killer strains, and the EX33 non-killer strain (Table 1). New killer yeasts were found only in two fermentations of grapes from the Albarregas (Barraecas in Latin) river valley and named Kbarr killer strains. These Kbarr yeasts remained in more than $50 \%$ of the total viable yeast cells at the tumultuous or end fermentation stages. Two types of Kbarr phenotypes were found, Kbarr-1 and Kbarr-2. The Kbarr-1 strains killed the Kbarr-2 (Figure 1) strains, while the Kbarr-2 strains did not kill the Kbarr1 strains (not shown). Two Kbarr-1 yeast isolates (EX1178 and EX1180) were selected for wine making according to the criteria described previously (Regodón et al., 1997), and therefore chosen for deeper killer phenotype and genotype analyses. Initially, no Kbarr-2 yeast isolate was chosen for such analysis because they showed lower killer activity than Kbarr-1 strains (Figures 1 and 2). All killer Kbarr isolates were prototrophic yeasts identified as T. delbrueckii according to their physiological characteristics (Kurtzman, 2011), 18S ribosomal RNA sequence (Maqueda et al., 2012), and ITS-RFLPs (Esteve-Zarzoso et al., 1999) analyses.

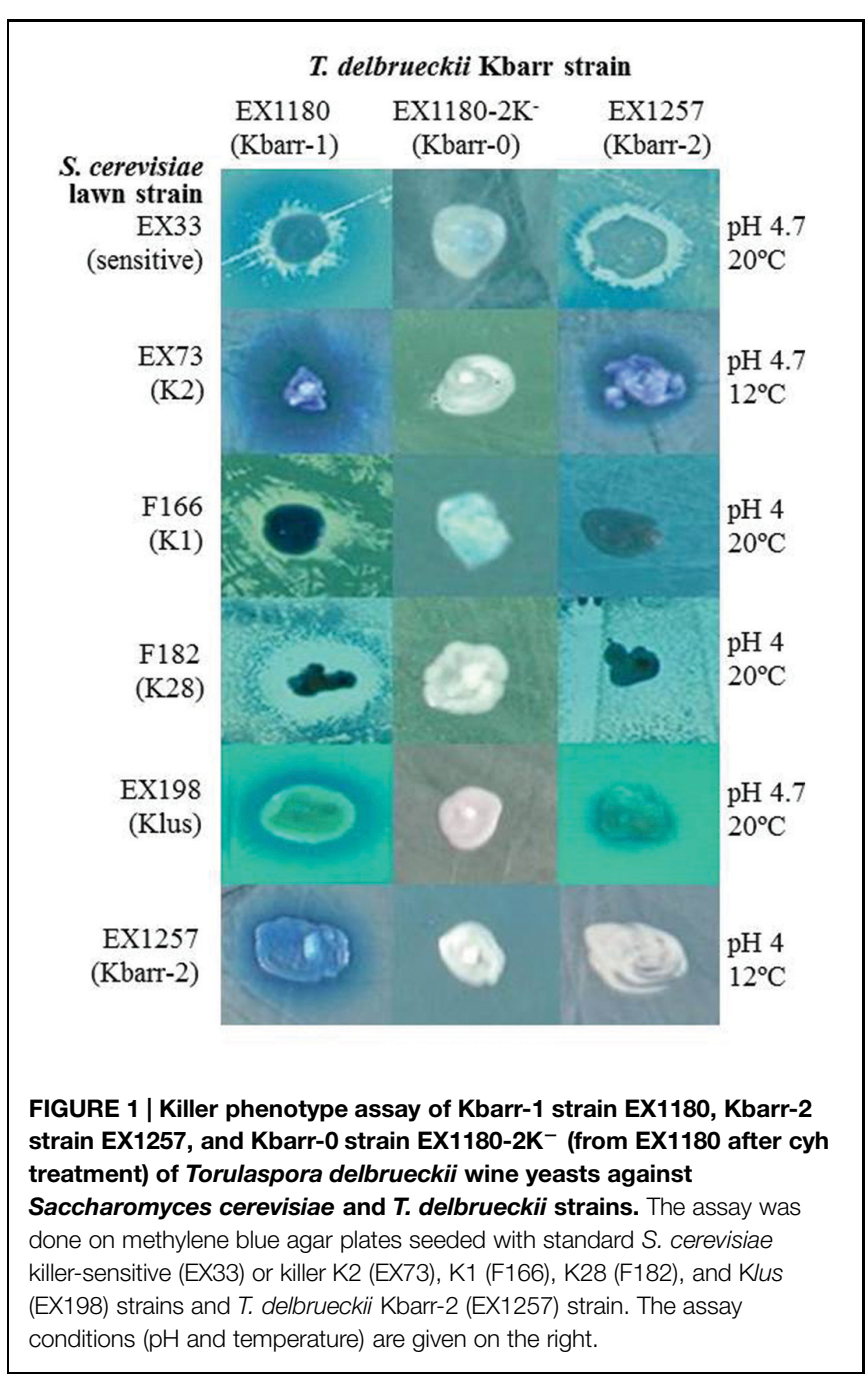


The Kbarr-1 strains killed the four known K1, K2, K28, and Klus killer strains of $S$. cerevisiae and the aforementioned T. delbrueckii Kbarr-2 strain, but they did not kill other Kbarr-1 yeasts (Figure 1). They were also lethal to yeast species other than $S$. cerevisiae, such as Hanseniaspora sp., Kluyveromyces lactis, Schizosaccharomyces pombe, Candida albicans, C. tropicalis, C. dubliniensis, C. kefir, C. glabrata, C. parasilopsis, C. krusei, Yarrowia lipolytica, and Hansenula mrakii, although unfortunately they did not kill the wine spoilage yeast Brettanomyces as it might have been desired (Figure 2). The Kbarr-1 strains were only weakly sensitive to killer toxins produced by $S$. cerevisiae Klus and $H$. mrakii, and resistant to the rest of the tested killer yeasts (not shown). The killing-activity spectrum of the Kbarr-1 yeasts was even broader than that of the recently discovered S. cerevisiae Klus yeasts (Rodríguez-Cousiño et al., 2011). Kbarr-1 yeasts showed stronger killer activity than $\mathrm{K} 2$ or Klus yeasts, and similar activity to those of $S$. cerevisiae $\mathrm{K} 1$, or K28 strains. The Kbarr-1's strongest activity was found at $\mathrm{pH} 4.7$ and $12^{\circ} \mathrm{C}$ against $S$. cerevisiae $\mathrm{K} 2, \mathrm{pH} 4$ and $20^{\circ} \mathrm{C}$ against S. cerevisiae $\mathrm{K} 28$, and $\mathrm{pH} 4.7$ and $20^{\circ} \mathrm{C}$ against $H$. mrakii, C. kefir, C. glabrata, C. dubliniensis, and Y. lipolytica strains (Figures 1 and 2).

\section{Genotypic Characterization of Kbarr-1 Killer Yeasts}

All Kbarr-1 killer strains carried two nucleic acid bands that showed an agarose-gel-electrophoresis mobility similar to those of viral dsRNAs from other killer yeasts: (1) a slower-moving band, similar in size to the dsRNA genome of ScV-LA virus (4.6 kb, now named the TdV-LAbarr band); and (2) a fastermoving band, similar to the dsRNA genome of ScV-M viruses (1.7 kb, now named the TdV-Mbarr-1 band; Figure $3 \mathrm{~A}$ ). The dsRNA nature of the two nucleic acid bands was confirmed by DNAse I and RNAse A treatments. The mtDNA disappeared after DNAse I treatment, while LA, M2, and Mlus dsRNAs used as controls, and the bands of similar sizes present in the Kbarr-1 strains, remained unaffected (Figure 3B). Additionally, LA, M2, Mlus dsRNA bands and the Kbarr-1 strain bands disappeared after RNAse A treatment, while mtDNA remained unaffected. Moreover, the RNA molecules were fairly resistant to RNAse A digestion in the presence of $0.5 \mathrm{M} \mathrm{NaCl}$, as expected for dsRNA but not for ssRNA (Berrye and Bevane, 1972; Vodkin and Fink, 1973; Cansado et al., 1999; Figure 3B). Mbarr-1 dsRNA was lost during the growth of Kbarr-1 strains in the presence of cycloheximide, and a concomitant loss of its killer activity was observed (Figure 3C). This result suggests that the Kbarr-1 killer phenotype is encoded by the Mbarr-1 dsRNAs, as has been previously described for the killer toxins encoded by M1, M2, M28, and Mlus dsRNAs in S. cerevisiae (Berrye and Bevane, 1972; Vodkin and Fink, 1973; Wickner, 1991; Rodríguez-Cousiño et al., 2011).

\section{Analysis of TdV-Mbarr-1 dsRNA Sequence and Kbarr-1 Preprotoxin ORF}

The TdV-Mbarr-1 dsRNA band present in the Kbarr-1 strain EX1180 was purified after agarose-gel electrophoresis and sequenced by NGS techniques (see Materials and Methods). The

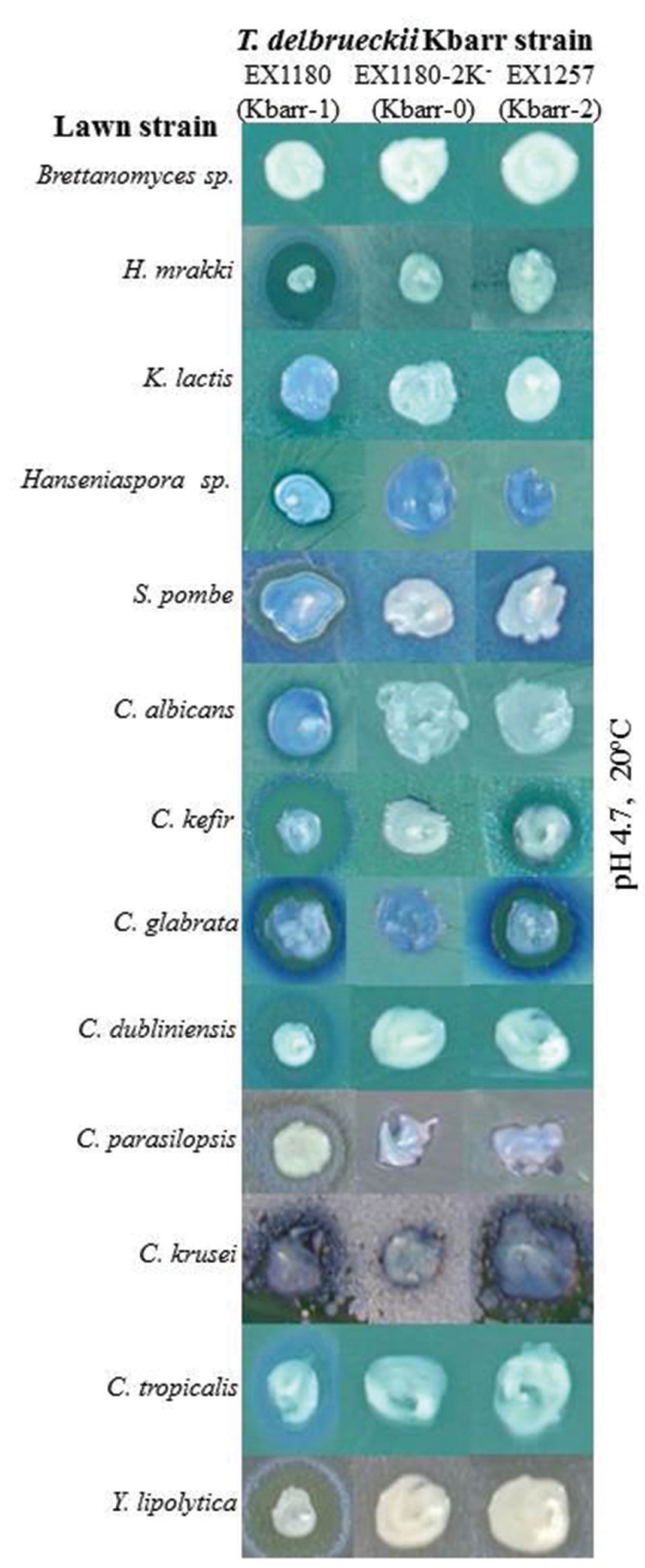

FIGURE 2 | Killer phenotype assay of Kbarr-1 strain EX1180, Kbarr-2 strain EX1257, and Kbarr-0 strain EX1180-2K- of T. delbrueckii wine yeasts against non-Saccharomyces yeasts (indicated on the left). The assay was done at $\mathrm{pH} 4.7$ and $20^{\circ} \mathrm{C}$.

full cDNA sequence determined was 1705 nucleotides, which is the same size as that estimated by agarose-gel electrophoresis, $1.7 \mathrm{~kb}$ (Figures 3 and 4 ; the $5^{\prime}-3^{\prime}$ orientation refers to the positive strand with coding capacity). There is a $5^{\prime}$ GAAAAA 
A

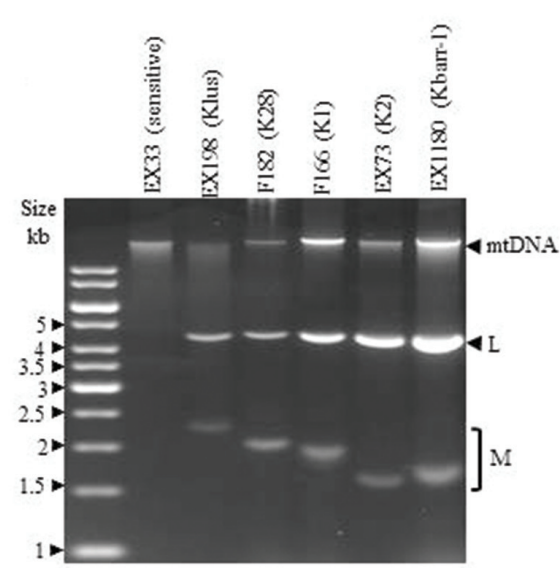

B

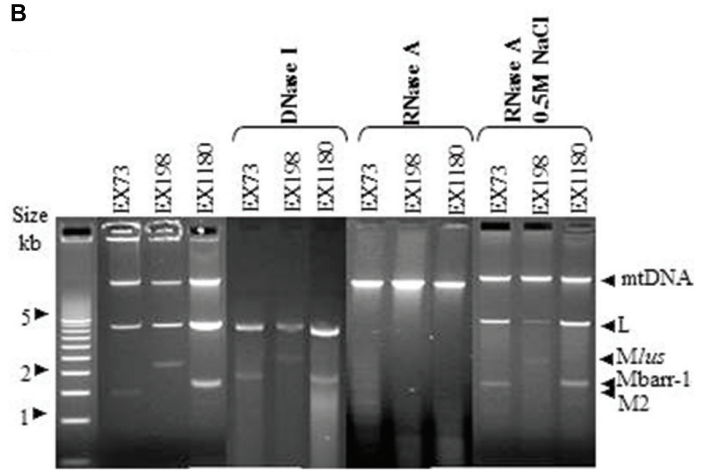

c

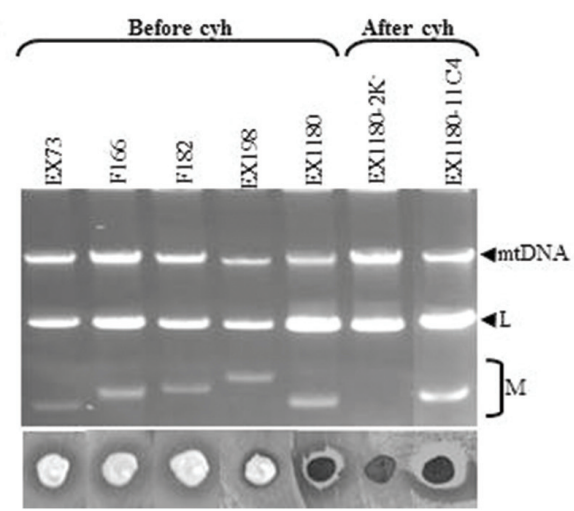

FIGURE 3 | Genetic determinants of Kbarr-1 phenotype. (A) Presence of $L$ and $M$ molecules in Kbarr-1 strains. Nucleic acids were obtained from sensitive (EX33), Klus (EX198), K28 (F182), K1 (F166), K2 (EX73), and Kbarr-1 (EX1180) strains, and separated by agarose gel electrophoresis. The ethidium bromide staining of the gel is shown. (B) Nuclease treatments. Total nucleic acids from strains K2 (EX73), Klus (EX198), and Kbarr-1 (EX1180), after DNAse I digestion, or after RNAse A treatment under low or high salt conditions, were separated by agarose gel electrophoresis. (C) Cycloheximide curing of killer Mbarr-1 virus. Agarose gel electrophoresis of total nucleic acids from killer K2 (EX73), K1 (F166), K28 (F182), Klus (EX198), and Kbarr-1 (EX1180) strains before virus curing with cycloheximide and after treatment with cycloheximide of two EX1180 clones losing or maintaining the M dsRNA (top panel). The killer phenotype assay is shown (bottom panel). EX1180-2Kis a cycloheximide-cured clone from EX1180, and EX1180-11C4 is a cycloheximide-non-cured clone from EX1180. The assay was done on methylene blue agar plates $\left(\mathrm{pH} 4,20^{\circ} \mathrm{C}\right)$ seeded with the S. cerevisiae $\mathrm{K} 28$ strain (F182) for the T. delbrueckii killer assay, or the S. cerevisiae K-0 sensitive strain EX33 for the rest of the S. cerevisiae killer assays. conserved motif previously found in the ScV L and $\mathrm{M}$ genomes and probably required for transcription initiation (Fujimura and Wickner, 1989), followed by an open reading frame for the putative preprotoxin of 271 amino acids in the $5^{\prime}$-most region, from nucleotides 9 to 821 . The central part of the RNA molecule contains an A-rich region with 78 adenine residues. The noncoding $3^{\prime}$-region is presumed to provide structural cis-elements required for RNA replication and encapsidation. A putative $3^{\prime}$ terminal recognition element ( $3^{\prime}$-TRE) from nucleotides 36 to 58 (numbering from the $3^{\prime}$ end) with a free energy of $\Delta G=-$ $4.9 \mathrm{kcal} / \mathrm{mol}$ was found; although it has no significant identity with previously described $3^{\prime}$-TRE elements required for ssRNA replication of S. cerevisiae viral RNAs. No putative viral binding site (VBS) with typical stem loop structure interrupted by an unpaired protruding A residue was found in this $3^{\prime}$-region, despite these typical VBSs having been reported in the same genome region of LA, M1, and M28 dsRNAs, but not in Mlus (Rodríguez-Cousiño et al., 2011), and being required for ssRNA binding to Gag-Pol protein and packaging (Wickner et al., 2013). However, 10 sequence stretches homologous to previously reported poly $(\mathrm{A})$ downstream regions (including regions of replication, replication-enhancement, and packaging signals) of several S. cerevisiae and Z. bailii $\mathrm{M}$ viral genomes were found in this TdV-Mbarr1 non-coding $3^{\prime}$-region, but not in the rest of the molecule (Figure 4). Apart from these similarities, the TdVMbarr-1 genome presented no relevant sequence identity with the known $\mathrm{M}$ virus genomes of yeasts, which, in terms of their overall sequences, themselves share no relevant sequence identity.

The ORF located in the $5^{\prime}$ region of Mbarr- 1 contains a stretch of hydrophobic amino acids at the amino terminus according to the Kyte-Doolittle hydrophilicity plot (Kyte and Doolittle, 1982). This is a possible $\mathrm{N}$-terminal secretion signal with a potential signal for peptidase cleavage. The ORF also presents six Kex2p/Kexlp processing sites and four potential sites for $\mathrm{N}$-glycosylation (Figure 4). However, as it was the case for the genomes, the Kbarr-1 amino acid sequence showed no relevant sequence identity with the known yeast killer protein toxins, which, in terms of their overall sequences, themselves share no relevant amino acid sequence homology.

\section{Discussion}

\section{Characterization of the New Kbarr-1 Killer Yeasts}

The wine T. delbrueckii killer yeasts are less frequently isolated from spontaneous must fermentations than other wine killer yeasts such as S. cerevisiae K2 or Klus (Maqueda et al., 2012). This is probably because $T$. delbrueckii has slower growth rate and less fermentation vigor than $S$. cerevisiae yeasts in the grape must medium, so that $S$. cerevisiae quickly overcomes $T$. delbrueckii at the beginning of must fermentation. Also, isolation of the less frequent $T$. delbrueckii yeast may be missed because it resembles very much the colony morphology of $S$. cerevisiae, with the two being easily confused. We have succeeded probably because the intense killer phenotype of the new T. delbrueckii Kbarr1 yeasts allowed them to dominate the tumultuous and end 


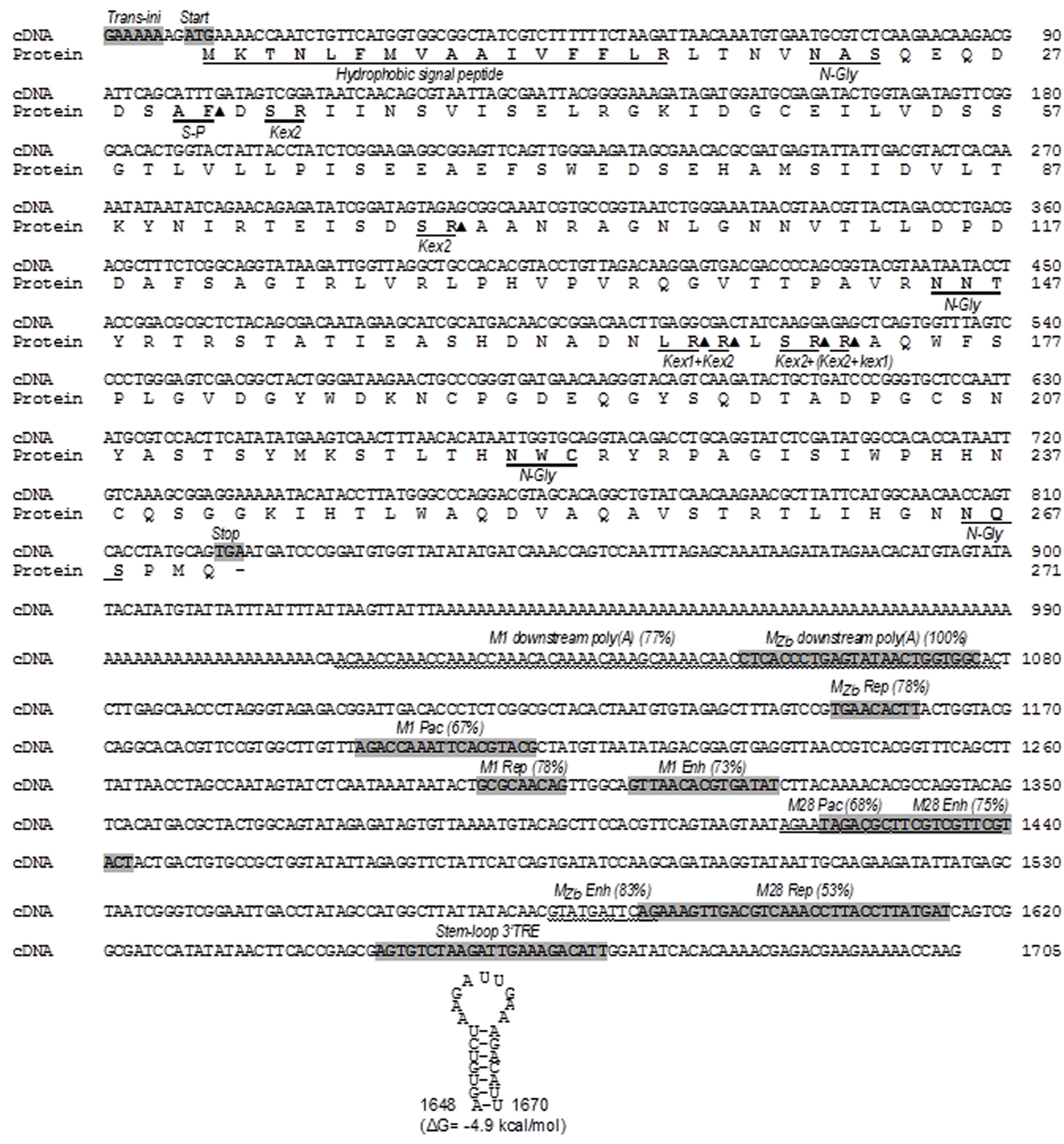

FIGURE 4 | Nucleotide sequence of the TdV-Mbarr-1 genome (cDNA) and the amino acid sequence of the ORF of the putative Kbarr-1 preprotoxin. The Kbarr-1 amino acid sequence is displayed under the nucleotide sequence. The 5' GAAAAA motif probably required for transcription initiation (trans-ini), the protein synthesis initiation codon (start), the protein synthesis stop codon (stop), the putative $3^{\prime}$-terminal recognition element for virus replication (stem-loop $3^{\prime}$ TRE) with a free energy of $\Delta G=-4.9 \mathrm{kcal} / \mathrm{mol}$, the two regions homologous to ScV-M1 and $\mathrm{M}_{Z b}$ dsRNAs located downstream from the central poly(A) [M1 downstream poly(A) and $\mathrm{M}_{Z b}$ downstream poly(A)], and the eight regions homologous to previously reported replication signals of ZbV-M $\mathrm{M}_{Z b}$ (M $\mathrm{M}_{Z b}$ Rep), ScV-M1 (M1 Rep), and ScV-M28 (M28 Rep), internal replication enhancers of ScV-M1 (M1 Enh), ScV-M28 (M28 Enh), and ZbV-M and ScV-M28 (M28 Pac) are shown shaded in the nucleotide sequence (except for ScV-M1 downstream poly(A), ScV-M28 (M28 Pac) and ZbV-M Mb (MZb-Enh) which are wavy underlined). The percentage of sequence identity is given in parentheses. The secondary structure of the putative cis signal for replication of TdV-Mbarr-1 RNA is at the bottom of the sequence. The hydrophobic signal peptide, the putative signal peptidase processing site (S-P), the putative Kex2 endopeptidase (Kex2) or Kex1 exopeptidase (Kex1) sites, and the potential N-glycosylation sites (N-Gly) are underlined in the amino acid sequence. Closed triangle, cleavage site. Sc, Saccharomyces cerevisiae; Zb, Zygosaccharomyces bailii.

stages of the spontaneous must fermentation that we analyzed, facilitating their isolation. As they can kill other S. cerevisiae strains as well as many other yeast species, they may have a beneficial effect during food fermentation, as it has been shown for K2 killer strains in winemaking (Pérez et al., 2001). This is especially relevant for the use of Torulaspora in winemaking 


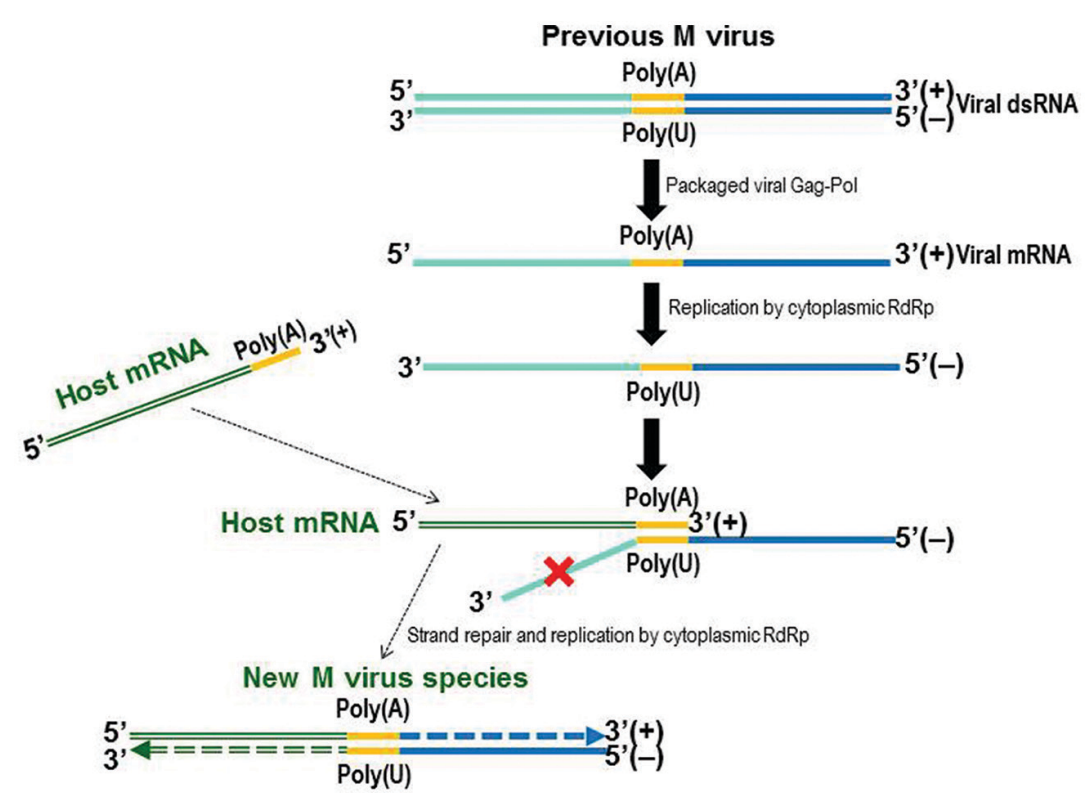

FIGURE 5 | Model of the emergence of the $\mathbf{M}$ virus species. Free mRNA (+) might be replicated to generate a ssRNA(-) instead of a natural dsRNA molecule, by a cytoplasmic RdRp that could be Pol of Gag-Pol of the LA virus. Complementary base pairing of the ssRNA(-) central poly(U) and the $3^{\prime}$ poly(A) of a host mRNA(+) may generate a new incomplete hybrid dsRNA molecule that could be repaired and replicated by the RdRp to yield a new dsRNA M virus.

because this species is strongly recommended by winemaking supply companies to improve wine quality, while the non-killer strains are quickly displaced by the always present $S$. cerevisiae yeasts during must fermentation. These Kbarr-1 yeasts may also be useful to avoid undesirable potential spoilage and pathogen yeasts in food fermentation processes because they have the broadest antifungal spectrum hitherto described (Figures 1 and 2), even broader than that of the recently described Klus killer yeasts (Rodríguez-Cousiño et al., 2013), or the other S. cerevisiae killer yeasts (K1, K2, or K28) that mostly kill sensitive cells of the same or some congeneric species (Magliani et al., 1997). Although the intensity of the Kbarr-1 killer activity may change depending on the assay conditions ( $\mathrm{pH}$, temperature, and the sensitive strain tested) as it happen for other killer toxins (Pfeiffer and Radler, 1984; Young, 1987), it is active against different yeast species in the typical food fermentation environment: acidic ( $\mathrm{pH} 3.5-5.5)$ and mild temperature $\left(18-28^{\circ} \mathrm{C}\right)$.

\section{Genetic Characterization of the Mbarr-1 Virus}

The Kbarr-1 killer yeasts contained two dsRNA molecules corresponding to a new TdV-Mbarr-1 dsRNA and the genome of its putative helper virus TdV-LAbarr, as found in other killer yeasts (Fujimura and Esteban, 2011, 2013; Rodríguez-Cousiño et al., 2011, 2013). The putative dependency of TdV-Mbarr-1 on TdV-LAbarr (and/or TdV-LBC) is likely because we never found Mbarr-1 killer yeasts without the $4.6 \mathrm{~kb}$ dsRNA among the 152 isolated yeasts. We never found killer Kbarr-1 yeast free of the $1.7 \mathrm{~kb}$ dsRNA, suggesting that the Kbarr-1 toxin is encoded by this RNA molecule. Moreover, this was confirmed by the Kbarr-1 yeasts becoming non-killer and sensitive to Kbarr-1 killer yeasts when they lost the $1.7 \mathrm{~kb}$ dsRNA after cycloheximide treatment.

\section{Mbarr-1 dsRNA Organization and the Encoded Kbarr-1 Preprotoxin}

The complete cDNA sequence of Mbarr-1 dsRNA (1705 nucleotides) matches the Mbarr-1 dsRNA size estimated by agarose-gel electrophoresis ( $1.7 \mathrm{~kb}$, Figure 4), and it includes the $5^{\prime}$ and $3^{\prime}$ ends, and the central A-rich region previously found in the $S$. cerevisiae $M$ viruses. This suggests that the NGS techniques used here for dsRNA sequencing yielded more satisfactory results than those we used previously for ScV-Mlus dsRNA sequencing, where the length of the sequence obtained (2033 nucleotides) was shorter than the $2.3 \mathrm{~kb}$ visualized on agarose gel electrophoresis (Rodríguez-Cousiño et al., 2011). This difference was explained as due to the variable number of adenine residues in the central A-rich region, which supposedly accounts for the different-sized ScV-Mlus isotypes. This central A-rich region may facilitate sliding or jumping of either the reverse transcriptase or the Taq polymerase used in RT-PCR, yielding a slightly shorter sequence than the actual. This methodological problem is overcome by using the new NGS sequencing approach, given that it yields the same sequence length as the actual dsRNA size. TdV-Mbarr- 1 contains a single continuous central A-rich region as do most of $\mathrm{M}$ dsRNAs (Wickner, 1996) with the exception of ScV-Mlus which contains two central A-rich regions of variable size (Rodríguez-Cousiño et al., 2011). Additionally, Mbarr-1 also resembles the ScV-M genomes in that it contains the conserved 5' GAAAAA motif probably required for transcription initiation, a putative $3^{\prime}$-TRE with low free energy, and 10 sequence stretches homologous to previously reported poly(A)-downstream-regions considered as putative signals for replication, replication-enhancement, and packaging, located in the non-coding $3^{\prime}$-region of the S. cerevisiae 
and Z. bailii $\mathrm{M}$ viral genomes (Weiler et al., 2002; Wickner et al., 2013; Figure 4). Overall, the genome organization of Mbarr-1 dsRNA resembles that of other toxin-encoding satellite viruses such as ScV-M1, ScV-M2, ScV-M28, ScV-Mlus, or Z. bailii $\mathrm{M}_{Z b}$ dsRNA (Schmitt and Breinig, 2002; Weiler et al., 2002; Rodríguez-Cousiño et al., 2011). The conserved motifs located in the non-coding $3^{\prime}$-region suggest a close phylogenic relationship of $T$. delbrueckii, S. cerevisiae, and $Z$. bailii $M$ viruses. The coding $5^{\prime}$-region of the $M$ viruses may have an independent origin, probably from host yeast genes coding for secreted proteins, given that a relevant amino acid sequence identity between the S. cerevisiae Klus toxin and the nuclear YFR020W ORF protein has been found (Rodríguez-Cousiño et al., 2011). Probably, the central A-rich region located between the coding $5^{\prime}$-region and the non-coding $3^{\prime}$-region of the $\mathrm{M}$ viruses is just a reminiscence of the mRNA $3^{\prime}$ poly(A)-tail of a hypothetically secreted and chromosomally encoded protein, which somehow became attached to the $5^{\prime}$ end of the viral-RNA, which in turn formed the non-coding $3^{\prime}$-region of the final M RNA. Thereafter, as shown in Figure 5, new $M$ viruses species can be generated by annealing of the $3^{\prime}$ poly(A)-tail of other incoming mRNA with the central poly $(U)$ of a pre-existing viral M ssRNA(-), followed by a conservative replication of the complementary strands by a cytoplasmic RdRp to create a distinct " 5 ' host mRNA-central poly(A)-3' viral RNA” hybrid RNA molecule. The RdRp required for this conservative replication could be provided by Pol of the Gag-Pol fusion protein of LA helper virus. Further studies will be required to confirm this hypothesis.

The AUG initiation codon of the putative Mbarr-1 preprotoxin ORF is located close to the $5^{\prime}$ end of the RNA molecule (Figure 4), like in M1, M28, and $\mathrm{M}_{Z b}$ RNAs (Skipper et al., 1984; Meskaukas, 1990; Schmitt and Tipper, 1995; Weiler et al., 2002) but different to the Mlus RNA whose AUG codon is located $112 \mathrm{nt}$ away from the $5^{\prime}$ end (Rodríguez-Cousiño et al., 2011). Also as for other M dsRNA, the Mbarr-1 ORF organization resembles that of other killer preprotoxins such as those of M1, M2, M28, or Mlus viruses. It contains a stretch of hydrophobic amino acids at the amino terminus, potential Kex2p/Kexlp processing sites, and potential sites for $\mathrm{N}$-glycosylation (Figure 4). Proteolytic cleavage of the Kbarr-1 preprotoxin by signal peptidase and Kex $2 /$ Kex 1 proteases could produce four putative peptides, the signal peptide and the $\alpha, \beta$, and $\gamma$ subunits. According to the disulphide bond prediction

\section{References}

Altschul, S. F., Gish, W., Miller, W., Myers, E. W., and Lipman, D. J. (1990). Basic local alignment search tool. J. Mol. Biol. 215, 403-410. doi: 10.1016/S00222836(05)80360-2

Altschul, S. F., Madden, T. L., Schäffer, A. A., Zhang, J., Zhang, Z., Miller, W., et al. (1997). Gapped BLAST and PSI-BLAST: a new generation of protein database search programs. Nucleic Acids Res. 25, 3389-3402. doi: 10.1093/nar/25. 17.3389

Azzolini, M., Tosi, E., Lorenzini, M., Finato, F., and Zapparoli, G. (2015). Contribution to the aroma of white wines by controlled Torulaspora delbrueckii cultures in association with Saccharomyces cerevisiae. World J. Microbiol. Biotechnol. 31, 277-293. doi: 10.1007/s11274-0141774-1
(Ceroni et al., 2006), there is a potential disulphide bond between cysteine-50, located in the putative $\alpha$ subunit, and cysteine-189 or cysteine-238, both located in the putative $\beta$ subunit of the Kbarr- 1 mature toxin. This disulphide bond may be required for keeping $\alpha$ and $\beta$ subunits together during the preprotoxin processing and secretion to yield an extracellular active $\alpha / \beta$ heterodimer.

\section{Conclusion}

The new $T$. delbrueckii Kbarr-1 wine yeasts kill all the tested $S$. cerevisiae strains as well as many other undesired yeast species in environmental conditions similar to those of the typical sugarrich substrate fermentation, which makes them an interesting starter culture for the food fermentation industry. The killer dsRNA virus system of this wine yeast seems very similar to those previously described in S. cerevisiae. Although there was no relevant general sequence identity among the $M$ genomes, the relevant identity found in 10 sequence stretches of TdV-Mbarr-1 RNA with previously reported M RNAs raises the possibility that the $M$ viruses may have a common phylogenic origin, at least for the non-coding $3^{\prime}$-region where these homologous sequences are located.

\section{Author Contributions}

MR conceived the project, $\mathrm{MR}, \mathrm{RV}$, and $\mathrm{MM}$ designed and performed the experiments, MR, AL-P, and JR analyzed the data, $\mathrm{MR}$ wrote and edited the manuscript.

\section{Acknowledgments}

This work was funded by grants GR10088 from the Extremadura Regional Government and AGL2011-25711 from the Spanish Ministry of Education and Science. RV acknowledges support by a fellowship from the Extremadura Regional Government. We thank the Unidad de Genómica Cantoblanco (Fundación Parque Científico de Madrid, Spain) for setting up the protocols for library preparation and sequencing of viral dsRNA, and the company Biotechvana S.L. (Technological Park of Valencia, Spain) for setting up the dsRNA sequence assembling strategy.

Berrye, A., and Bevane, A. (1972). A new species of double-stranded RNA from yeast. Nature 239, 279-280. doi: 10.1038/239279a0

Cansado, J., Barros Velázquez, J., Sieiro, C., Gacto, M., and Villa, T. G. (1999). Presence of non-suppressive. M2-related dsRNAs molecules in Saccharomyces cerevisiae strains isolated from spontaneous fermentations. FEMS Microbiol. Lett. 181, 211-215.

Ceroni, A., Passerini, A., Vullo, A., and Frasconi, P. (2006). DISULFIND: a disulfide bonding state and cysteine connectivity prediction server. Nucleic Acids Res. 34, W177-W181. doi: 10.1093/nar/ $\mathrm{gkl} 266$

Ciani, M., Comitini, F., Mannazzu, I., and Domizio, P. (2010). Controlled mixed culture fermentation: a new perspective on the use of non-Saccharomyces yeasts in winemaking. FEMS Yeast Res. 10, 123-133. doi: 10.1111/j.1567-1364.2009. 00579.x 
Díez, B., Pedrós-Alió, C., Marsh, T. L., and Massana, R. (2001). Application of denaturing gradient gel electrophoresis (DGGE) to study the diversity of marine picoeukaryotic assemblages and comparison of DGGE with other molecular techniques. Appl. Environ. Microbiol. 67, 2942-2951. doi: 10.1128/AEM.67.7.2942-2951.2001

Dinman, J. D., and Wickner, R. B. (1992). Ribosomal frameshifting efficiency and gag/gag-pol ratio are critical for yeast M1 double-stranded RNA virus propagation. J. Virol. 66, 3669-3676.

Esteve-Zarzoso, B., Belloch, C., Uruburu, F., and Querol, A. (1999). Identification of yeasts by RFLP analysis of the 5.85 rRNA gene and the two ribosomal internal transcribed spacers. Int. J. Syst. Bacteriol. 49, 329-337. doi: 10.1099/0020771349-1-329

Fujimura, T., and Esteban, R. (2011). Cap-snatching mechanism in yeast L-A double-stranded RNA virus. Proc. Natl. Acad. Sci. U.S.A. 108, 17667-17671. doi: $10.1073 /$ pnas. 1111900108

Fujimura, T., and Esteban, R. (2013). Cap snatching in yeast L-BC double-stranded RNA totivirus. J. Biol. Chem. 288, 23716-23724. doi: 10.1074/jbc.M113. 490953

Fujimura, T., Esteban, R., Esteban, L. M., and Wickner, R. B. (1990). Portable encapsidation signal of the L-A double-stranded-RNA virus of Saccharomyces cerevisiae. Cell 62, 819-828. doi: 10.1016/0092-8674(90) 90125-X

Fujimura, T., Ribas, J. C., Makhov, A. M., and Wickner, R. B. (1992). Pol of gagpol fusion protein required for encapsidation of viral RNA of yeast L-A virus. Nature 359, 746-749. doi: 10.1038/359746a0

Fujimura, T., and Wickner, R. B. (1989). Reconstitution of template-dependent in vitro transcriptase activity of a yeast double-stranded RNA virus. J. Biol. Chem. 264, 10872-10877.

Futami, R., Muñoz-Pomer, L., Dominguez-Escriba, L., Covelli, L., Bernet, G. P., and Sempere, J. M. (2011). GPRO The professional tool for annotation, management and functional analysis of omic databases. Biotech. Bioinform. SOFT 3, 2011.

González-Royo, E., Pascual, O., Kontoudakis, N., Esteruelas, M., EsteveZarzoso, B., Mas, A., et al. (2014). Oenological consequences of sequential inoculation with non-Saccharomyces yeasts (Torulaspora delbrueckii or Metschnikowia pulcherrima) and Saccharomyces cerevisiae in base wine for sparkling wine production. Eur. Food Res. Technol. 240, 999-1012.

Guthrie, C., and Fink, G. R. (1991). Guide to yeast genetics and molecular biology. Methods Enzymol. 194, 3-57.

Icho, T., and Wickner, R. B. (1989). The double-stranded RNA genome of yeast virus L-A encodes its own putative RNA polymerase by fusing two open reading frames. J. Biol. Chem. 264, 6716-6723.

Jolly, J., Augustyn, O., and Pretorius, I. (2006). The role and use of nonSaccharomyces yeasts in wine production. S. Afr. J. Enol. Viticul. 27, 15.

Kaiser, C., Michaelis, S., and Mitchell, A. (1994). Methods in Yeast Genetics. New York: Cold Spring Harbor Laboratory Press.

Kurtzman, C. P. (2011). “Torulaspora Lindner (1904)," in The Yeasts: A Taxonomic Study, 5th Edn, eds C. P. Kurtzman, J. W. Fell, and T. Boekhout (London: Elsevier), 867-874

Kyte, J., and Doolittle, R. (1982). A simple method for displaying the hydropathic character of a protein. J. Mol. Biol. 157, 105-132. doi: 10.1016/00222836(82)90515-0

Langmead, B., and Salzberg, S. (2012). Fast gapped-read alignment with Bowtie 2. Nat. Methods 9, 357-359. doi: 10.1038/nmeth.1923

Langmead, B., Trapnell, C., Pop, M., and Salzberg, S. L. (2009). Ultrafast and memory-efficient alignment of short DNA sequences to the human genome. Genome Biol. 10, .21-.25. doi: 10.1186/gb-2009-10-3-r25

Luo, R., Liu, B., Xie, Y., Li, Z., Huang, W., Yuan, J., et al. (2012). SOAPdenovo2: an empirically improved memory-efficient short-read de novo assembler. Gigascience 1, 18-24. doi: 10.1186/2047-217X-1-18

Magliani, W., Conti, S., Gerloni, M., Bertolotti, D., and Polonelli, L. (1997). Yeast killer systems. Clin. Microbiol. Rev. 10, 369-400.

Maqueda, M., Zamora, E., Álvarez, M. L., and Ramírez, M. (2012). Characterization, ecological distribution, and population dynamics of Saccharomyces "sensu stricto" killer yeasts in the spontaneous grape-must fermentations of south-western Spain. Appl. Environ. Microbiol. 78, 735-743. doi: 10.1128/AEM.06518-11
Maqueda, M., Zamora, E., Rodríguez-Cousiño, N., and Ramírez, M. (2010). Wine yeast molecular typing using a simplified method for simultaneously extracting mtDNA, nuclear DNA and virus dsRNA. Food Microbiol. 27, 205-209. doi: 10.1016/j.fm.2009.10.004

Medlin, L., Elwood, H. J., Stickel, S., and Sogin, M. L. (1988). The characterization of enzymatically amplified eukaryotic 16S-like rRNA-coding regions. Gene 71, 491-499. doi: 10.1016/0378-1119(88)90066-2

Meskaukas, A. (1990). Nucleotide sequence of cDNA to yeast M2-1 dsRNA segment. Nucleic Acids Res. 18, 6720. doi: 10.1093/nar/18.22.6720

Nissen, P., Nielsen, D., and Arneborg, N. (2003). Viable Saccharomyces cerevisiae cells at high concentrations cause early growth arrest of non-Saccharomyces yeasts in mixed cultures by a cell-cellcontact-mediated mechanism. Yeast 20, 331-341. doi: 10.1002/yea.965

Park, C. M., Lopinski, J. D., Masuda, J., Tzeng, T. H., and Bruen, J. A. (1996). A second double-stranded RNA virus from yeast. Virology 216, 451-454. doi: 10.1006/viro.1996.0083

Pérez, F., Ramírez, M., and Regodón, J. A. (2001). Influence of killer strains of Saccharomyces cerevisiae on wine fermentation. Antonie Leeuwenhoek J. Microbiol. 79, 393-399. doi: 10.1023/A:1012034608908

Pfeiffer, P., and Radler, F. (1984). Comparison of the killer toxin of several yeasts and the purification of a toxin of type K2. Arch. Microbiol. 137, 357-361. doi: 10.1007/BF00410734

Ramírez, M., Vinagre, A., Ambrona, J., Molina, F., Maqueda, M., and Rebollo, J. E. (2004). Genetic instability of heterozygous hybrid populations of natural wine yeasts. Appl. Environ. Microbiol. 70, 4686-4691. doi: 10.1128/AEM.70.8.46864691.2004

Regodón, J. A., Pérez, F., and Ramírez, M. (1997). A simple and effective procedure for selection of wine yeast strains. Food Microbiol 14, 247-254. doi: 10.1006/fmic.1996.0091

Renault, P. E., Albertin, W., and Bely, M. (2013). An innovative tool reveals interaction mechanisms among yeast populations under oenological conditions. Appl. Microbiol. Biotechnol 97, 4105-4119. doi: 10.1007/s00253012-4660-4665

Rodríguez-Cousiño, N., Gómez, P., and Esteban, R. (2013). L-A-lus, a new variant of the L-A Totivirus found in wine yeasts with Klus killer toxin-encoding Mlus double-stranded RNA: possible role of killer toxin-encoding satellite RNAs in the evolution of their helper viruses. Appl. Environ. Microbiol. 79, 4661-4674. doi: 10.1128/AEM.00500-13

Rodríguez-Cousiño, N., Maqueda, M., Ambrona, J., Zamora, E., Esteban, E., and Ramírez, M. (2011). A new wine Saccharomyces cerevisiae double-stranded RNA virus encoded killer toxin (Klus) with broad antifungal activity is evolutionarily related to a chromosomal host gene. Appl. Environ. Microbiol. 77, 1822-1832. doi: 10.1128/AEM.02501-10

Sambrook, J., Fritsch, E. F., and Maniatis, T. (1989). Molecular Cloning: A Laboratory Manual. New York: Cold Spring Harbor Laboratory Press.

Sangorrín, M. P., Lopes, C. A., Giraudo, M. R., and Caballero, A. C. (2007a). Diversity and killer behaviour of indigenous yeasts isolated from the fermentation vat surfaces in four Patagonian wineries. Int. J. Food Microbiol. 119, 351-357. doi: 10.1016/j.ijfoodmicro.2007. 04.010

Sangorrín, M. P., Lopes, C. A., Jofré, V., Querol, A., and Caballero, A. C. (2007b). Spoilage yeasts from Patagonian cellars: characterization and potential biocontrol based on killer interactions. World J. Microbiol. Biotechnol. 24, 945-953. doi: 10.1007/s11274-007-9557-6

Schmitt, M. J., and Breinig, F. (2002). The viral killer system in yeast: from molecular biology to application. FEMS Microbiol. Rev. 748, 1-20.

Schmitt, M. J., and Breinig, F. (2006). Yeast viral killer toxins: lethality and self-protection. Nat. Rev. Microbiol. 4, 212-221. doi: 10.1038/nrmicr o1347

Schmitt, M. J., and Tipper, D. J. (1995). Sequence of the M28 dsRNA: preprotoxin is processed to an a/b heterodimeric protein. Virology 213, 341-351. doi: $10.1006 /$ viro.1995.0007

Skipper, N., Thomas, D. Y., and Lau, P. C. K. (1984). Cloning and sequencing of the preprotoxin-coding region of the yeast M1 double-stranded RNA. EMBO J. 3, 107-111.

Thorvaldsdottir, H., Robinson, J. T., and Mesirov, J. P. (2013). Integrative Genomics Viewer (IGV): high-performance genomics data visualization and exploration. Brief. Bioinform. 14, 178-192. doi: 10.1093/bib/bbs017 
Vodkin, M. H., and Fink, G. R. (1973). A nucleic acid associated with a killer strain of yeast. Proc. Natl. Acad. Sci. U.S.A. 70, 1069-1072. doi: 10.1073/pnas.70. 4.1069

Weiler, F., Rehfeldt, K., Bautz, F., and Schmitt, M. J. (2002). The Zygosaccharomyces bailii antifungal virus toxin zygocin: cloning and expression in a heterologous fungal host. Mol. Microbiol. 46, 1095-1105. doi: 10.1046/j.1365-2958.2002.03225.x

Wickner, R. B. (1991). "Yeast RNA virology: the killer systems," in The Molecular and Cellular Biology of the Yeast Saccharomyces: Genome Dynamics, Protein Synthesis, and Energetics, eds J. R. Broach, J. R. Pringle, and E. W. Jones (Cold Spring Harbor, NY: Cold Spring Habor Laboratory Press), 263-296.

Wickner, R. B. (1996). Double-stranded RNA viruses of Saccharomyces cerevisiae. Microbiol. Rev. 60, 250-265.

Wickner, R. B., Bussey, H., Fujimura, T., and Esteban, R. (1995). "Viral RNA and the killer phenomenon of Saccharomyces," in The Mycota. Genetics and Biotechnology, Vol. II, ed. U. Kück (Berlin: Springer Verlag), 211-226.
Wickner, R. B., Fujimura, T., and Esteban, R. (2013). Viruses and prions of Saccharomyces cerevisiae. Adv. Virus Res. 86, 1-36. doi: 10.1016/B978-0-12394315-6.00001-5

Young, T. W. (1987). "Killer yeasts," in The Yeasts, eds A. H. Rose and J. S. Harrison (London: Academic Press), 131-164.

Conflict of Interest Statement: The authors declare that the research was conducted in the absence of any commercial or financial relationships that could be construed as a potential conflict of interest.

Copyright ( 2015 Ramírez, Velázquez, Maqueda, López-Piñeiro and Ribas. This is an open-access article distributed under the terms of the Creative Commons Attribution License (CC BY). The use, distribution or reproduction in other forums is permitted, provided the original author(s) or licensor are credited and that the original publication in this journal is cited, in accordance with accepted academic practice. No use, distribution or reproduction is permitted which does not comply with these terms. 